Pathophysiology of Haemostasis and Thrombosis
Pathophysiol Haemost Thromb 2005;34:18-22

DOI: $\underline{10.1159 / 000088543}$
Received: January 31, 2005

Accepted after revision: June 28, 2005

\title{
Preexisting Antibodies to Platelet Factor 4- Heparin Complexes in Patients with Acute Coronary Syndrome Who Have No History of Heparin Exposure
}

\author{
Takefumi Matsuo $^{\mathrm{a}}$ Shunji Suzuki ${ }^{\mathrm{a}}$ Miyako Matsuo ${ }^{\mathrm{b}}$ Hiroko Kobayasi $^{\mathrm{b}}$ \\ ${ }^{\mathrm{a}}$ Internal Medicine and ${ }^{\mathrm{b}}$ Clinical Laboratory, Hyogo Prefectural Awaji Hospital, Sumoto, Japan
}

\section{Key Words}

Heparin-induced thrombocytopenia $\cdot$ Heparinplatelet factor 4 complex antibodies - Acute coronary syndrome $\cdot$ Thrombotic complications

\begin{abstract}
Preexisting heparin-induced thrombocytopenia (HIT) antibodies are detected in some patients who have not previously been exposed to any kind of heparin. However, the role of preexisting HIT antibodies in acute coronary syndrome (ACS) is still unknown. This study was carried out to clarify the role of preexisting HIT antibodies in patients with ACS. Forty patients with ACS who had not been exposed to any kind of heparin via the venous or subcutaneous route or heparin-coated materials and had undergone percutaneous coronary intervention (PCl) under heparin anticoagulation within $6 \mathrm{~h}$ from the onset of ACS were chosen from the medical records in the cardiac emergency department. As a control of the ACS patients, 51 patients with angina pectoris who underwent elective $\mathrm{PCl}$ under heparin anticoagulation were chosen in the same manner as the ACS patients. Preexisting HIT antibodies were detected by ELISA in 6 patients. Two of the 6 patients developed HIT and 1 patient experienced thrombosis requiring intracoronary thrombolytic therapy. Thrombotic complications during and immediately
\end{abstract}

after $\mathrm{PCl}$ in the very early stage after heparin administration were found in 4 of 6 patients with preexisting HIT antibodies. The frequency of preexisting HIT antibodies in ACS patients was significantly increased in comparison with that in non-ACS patients. The odds ratio of the risk of thrombotic complication between ACS and nonACS patients was estimated at 8.82 (95\% Cl: 1.3-63). Also, preexisting HIT antibodies in ACS patients significantly increased the risk of thrombotic complications compared with ACS without preexisting HIT antibodies. In conclusion, ACS patients with positive HIT antibodies have an increased risk of thrombotic complications during $\mathrm{PCl}$ performed under anticoagulation with heparin.

Copyright (C) 2005 S. Karger AG, Basel

\section{Introduction}

Heparin is routinely administered to patients with acute coronary syndrome (ACS) as an anticoagulant during cardiac intervention. Heparin-induced thrombocytopenia (HIT) has been reported to occur less frequently after an initial heparin administration, due to an immunological mechanism involving the formation of complexes between exogenous heparin from animal sources and antibodies to platelet factor 4 (PF4)-heparin complexes. HIT can often lead to arterial, venous or micro-

\section{KARGER}

Fax +4161306 1234 E-Mail karger@karger.ch www.karger.com
(C) 2005 S. Karger AG, Basel

1424-8832/05/0341-0018\$22.00/0

Accessible online at: www.karger.com/pht
Takefumi Matsuo

Internal Medicine, Hyogo Prefectural Awaji Hospital

1-1-6, Shimogamo

Sumoto, 656-0013 (Japan)

Tel. +81 79922 1200, Fax +81 79924 5704, E-Mail matsuo@awaji-hosp.sumoto.hyogo.jp 
vascular thrombosis. Thrombocytopenia in HIT is mainly mediated by immune complexes comprising antibodies to PF4-heparin complex and PF4-heparin complex as antigen in circulation. The immune complex can bind to FcyRIIa receptors on the surface of platelets, and activated platelets release procoagulant materials into the circulation. Finally, HIT sets up a hypercoagulability.

Although the onset of classical HIT has been reported to be 5-14 days after heparin anticoagulation, HIT antibodies were detected in cardiac patients who had not been exposed to heparin using an immune antigen assay [1]. The frequency of preexisting HIT antibodies is estimated at $1.4 \%$ in normal, $4.5 \%$ in elderly, $4.8 \%$ in pregnant and $8.6 \%$ in diabetic subjects [2]. To explain the preexistence of HIT antibodies, it was proposed that heparin-like molecules (glycosaminoglycans) on injured endothelium bind with PF4 to form complexes with which the antibodies react. Neoantigens appeared to cause conformational change of PF4 to induce the production of heterogenetic antibodies in the Ig subclass in the presence of heparinlike molecules. In ACS, a high level of PF4 associated with the activated platelets facilitates production of heparin on therapeutic heparin infusion [3]. HIT would be likely to develop in ACS patients with preexisting HIT antibodies. Also, HIT is known to be complicated by thrombosis in the presence of HIT antibodies. This study was carried out to clarify whether preexisting HIT antibodies can be used to predict the risk of thrombotic complications during or after cardiac intervention in ACS.

\section{Materials and Methods}

Forty consecutive patients with ACS were chosen based on the following criteria: no exposure to heparin confirmed in their medical records and the performance of percutaneous coronary intervention (PCI) within $6 \mathrm{~h}$ of the onset of ACS. ACS was diagnosed based on clinical symptoms, electrocardiographic ST change with or without Q waves, creatine kinase MB isozyme elevation, and left ventricular dysfunction of the infarct area as evaluated using left ventricular angiography and echocardiograms. Among non-ACS patients with no history of heparin exposure confirmed in their medical records, 51 consecutive patients with a stable angina pectoris were selected as controls from medical records covering the same period as the survey of ACS patients. The diagnosis of nonACS patients was based on clinical symptoms and an exercise tolerance test. In all subjects, culprit lesions of the coronary artery were clearly demonstrated by coronary angiography. The two groups showed no differences in age, gender, and risk factors such as frequency of hypertension, diabetes mellitus, cholesterol level, high-density lipoprotein concentrations, smoking habits or BMI (table 1). High levels of triglyceride were found in non-ACS patients. Follow-up platelet counts were routinely done before, at the
Table 1. Characteristics of the subjects

\begin{tabular}{lclc}
\hline & $\begin{array}{l}\text { ACS } \\
(\mathrm{n}=40)\end{array}$ & $\begin{array}{l}\text { Non-ACS } \\
(\mathrm{n}=51)\end{array}$ & $\begin{array}{l}\mathrm{p} \\
\text { value }\end{array}$ \\
\hline Gender, males/females & $29 / 11$ & $36 / 15$ & 0.84 \\
Age, years & $64.4 \pm 2.0$ & $64.6 \pm 1.6$ & 0.84 \\
Body mass index & $24.1 \pm 0.7$ & $24.5 \pm 0.4$ & 0.63 \\
Hypertension & $28(70)$ & $27(53)$ & 0.10 \\
Total cholesterol, mg/dl & $199 \pm 6.4$ & $211 \pm 6.5$ & 0.19 \\
Triglyceride, mg/dl & $96 \pm 9.4$ & $156 \pm 9.4$ & $<0.001$ \\
High-density lipoprotein, mg/dl & $40 \pm 1.5$ & $45 \pm 3.5$ & 0.16 \\
Diabetes mellitus & $17(43)$ & $13(25)$ & 0.09 \\
Active smokers & $28(70)$ & $27(53)$ & 0.10 \\
\hline
\end{tabular}

Figures in parentheses represent percentage.

end of, and 5 days after heparin treatment. Frozen serum samples obtained before heparin treatment were examined for heparin-PF4 complex antibodies (HIT antibodies). The measurement of HIT antibodies was carried out with an ELISA (Assrachrom HPIA, Stago, France). Using this assay, the optical density at $492 \mathrm{~nm}$ for HIT antibodies in 78 cardiac inpatients with normal platelet counts and no heparin exposure at the time of blood sampling was measured. The mean $\pm 3 \mathrm{SD}$ was $0.101 \pm 0.230$. None of the samples exceeded 0.47 , the positive cutoff point according to the instruction manual. In samples positive for HIT antibodies, a heparin-induced platelet aggregation test was subsequently performed [4]. A maximal platelet aggregation of $>20 \%$ at $0.5 \mathrm{U} / \mathrm{ml}$ of heparin and minimal aggregation to $100 \mathrm{U} / \mathrm{ml}$ were considered positive in this assay.

All subjects requiring coronary angiography took $81 \mathrm{mg}$ of aspirin. The patients with indications of PCI were routinely administered a bolus of 5,000 $\mathrm{U}$ of heparin and thereafter $500 \mathrm{U} / \mathrm{h}$. The dose and duration of heparin treatment were monitored by APTT at a range of 1.5-2.0 times the baseline. Thrombotic complications during and after PCI were estimated based on retested angiographic findings at the site of dilated and other segments in association with the clinical and electrocardiographic recurrence of myocardial ischemia. The findings included intramural thrombosis and intraluminal thrombus extension with or without extensive plaque fissuring. To treat the occlusion due to thrombosis, intracoronary thrombolysis with urokinase was conducted. When coronary reflow was obtained at less than $75 \%$ stenosis, the occlusion was considered a thrombotic complication [5]. PCI was performed in both ACS and non-ACS. There were no significant differences between the groups in the extent to which the coronary artery was affected and the stenosis of target vessels. The inhospital mortality rate in both groups was $0 \%$. No CABG was indicated in the groups with further thrombotic complications.

The study was carried out according to the principles of the Declaration of Helsinki and was performed with the agreement of the ethics committee in the department of cardiology. Data were analyzed using the unpaired Student $t$ test. Categorical variables were compared using the $\chi^{2}$ test, and odds ratios with confidence intervals $(\mathrm{CI})$ are presented. A $\mathrm{p}$ value of $<0.05$ was taken to represent significant difference. 
Table 2. Clinical characteristics of 7 patients with preexisting HIT antibodies

\begin{tabular}{lllllllll}
\hline No. & $\begin{array}{l}\text { Clinical } \\
\text { diagnosis }\end{array}$ & $\begin{array}{l}\text { Age } \\
(\mathrm{sex})\end{array}$ & $\begin{array}{l}\text { Main } \\
\text { coronary } \\
\text { artery lesion }\end{array}$ & $\begin{array}{l}\text { Throm- } \\
\text { botic } \\
\text { occlusion }\end{array}$ & $\begin{array}{l}\text { a } \\
\text { adminis- } \\
\text { adration, h }\end{array}$ & $\begin{array}{l}\text { Reduction of } \\
\text { platelet count } \\
\text { at heparin } \\
\text { cessation, } \%\end{array}$ & $\begin{array}{l}\text { Preexisting } \\
\text { HIT antibodies }\end{array}$ \\
\hline 1 & ACS & $67(\mathrm{M})$ & CX & - & 12 & 19.4 & + & - \\
2 & ACS & $59(\mathrm{M})$ & RCA & + & 1 & 20.3 & + & + \\
$3^{\mathrm{b}}$ & ACS & $57(\mathrm{M})$ & LAD & - & 9 & 61.8 & + & - \\
$4^{\mathrm{c}}$ & ACS & $75(\mathrm{M})$ & RCA & + & 8 & 42.5 & + & + \\
5 & ACS & $63(\mathrm{M})$ & RCA & + & 6 & 23.2 & + & - \\
6 & ACS & $69(\mathrm{M})$ & LAD & + & 9 & 16.2 & + & + \\
7 & non-ACS & $62(\mathrm{~F})$ & LAD & - & 48 & 21.7 & + & - \\
\hline
\end{tabular}

HIPA = Heparin-induced platelet aggregation; $\mathrm{CX}=$ left circumflex coronary artery; RCA = right coronary artery; LAD = left anterior descending artery.

${ }^{a}$ Failure of repeated angioplasty and required thrombolytic therapy.

${ }^{\mathrm{b}}$ HIT.

${ }^{\mathrm{c}}$ HIT with thrombosis.

\section{Results}

HIT antibodies before heparin infusion, preexisting HIT antibodies, were found in 6 of 40 ACS patients who had never been exposed to heparin and in 1 of the nonACS patients. Preexisting HIT antibodies were more common in ACS patients $(\mathrm{p}=0.03)$. Two patients developed thrombocytopenia 9 and $8 \mathrm{~h}$ after the administration of heparin, respectively. These 2 patients were diagnosed with HIT, 1 patient having $>50 \%$ thrombocytopenia with no other cause, and the other patient $>30 \%$ thrombocytopenia complicated by thrombotic occlusion during PCI (table 2). Three of 4 positive patients without thrombocytopenia showed thrombotic complications during and after PCI. Although there were no significant differences in mean age or other risk factors mentioned in table 1 between ACS patients with and without preexisting HIT antibodies, significant differences were found in both groups and included a more prominent reduction in the platelet count $(p=0.02)$ and more frequent formation of a thrombus (odds ratio 8.2, CI: $1.4-63.2, \mathrm{p}=$ 0.026) (table 3). In non-ACS patients, no HIT was found and 1 patient without preexisting HIT antibodies developed a thrombus during PCI. Thrombotic complications requiring thrombolytic therapy were found in 10 patients of the ACS group and 1 patient of the non-ACS group. The frequency of thrombotic complications was significantly higher in the ACS than the non-ACS group $(\mathrm{p}=0.003)$.
Table 3. Thrombotic complications in ACS patients with and without preexisting HIT antibodies

\begin{tabular}{llll}
\hline $\begin{array}{l}\text { Preexisting } \\
\text { HIT antibodies }\end{array}$ & $\begin{array}{l}\text { Thrombocytopenia } \\
(>30 \% \text { fall }) \\
\text { at end of heparin }\end{array}$ & $\begin{array}{l}\text { Thrombotic } \\
\text { complica- } \\
\text { tions }\end{array}$ & $\begin{array}{l}\text { Odds ratio } \\
(95 \% \mathrm{CI}) \\
\mathrm{p} \text { value }\end{array}$ \\
\hline Positive $(\mathrm{n}=6)$ & 2 & 4 & $9.3(1.4-63.2)$ \\
Negative $(\mathrm{n}=34)$ & 0 & 6 & $\mathrm{p}=0.026$
\end{tabular}

Platelet counts in ACS patients were significantly reduced on cessation of heparin treatment and returned to preheparin levels. No significant reduction in the platelet count was induced by the administration of heparin in non-ACS patients (fig. 1).

Optical densities obtained from ELISA in both groups showed significantly higher titers in ACS than non-ACS ( $p<0.01)$ (fig. 2). The level of HIT antibodies was higher in ACS with negative titers than in non-ACS with negative titers $(\mathrm{p}<0.05)$. ACS patients had a much greater chance of generating HIT antibodies than nonACS patients. Preexisting HIT antibodies detected by ELISA appeared more frequently in ACS patients and facilitated thrombotic complications during and immediately after PCI under anticoagulation with heparin (table 3). 


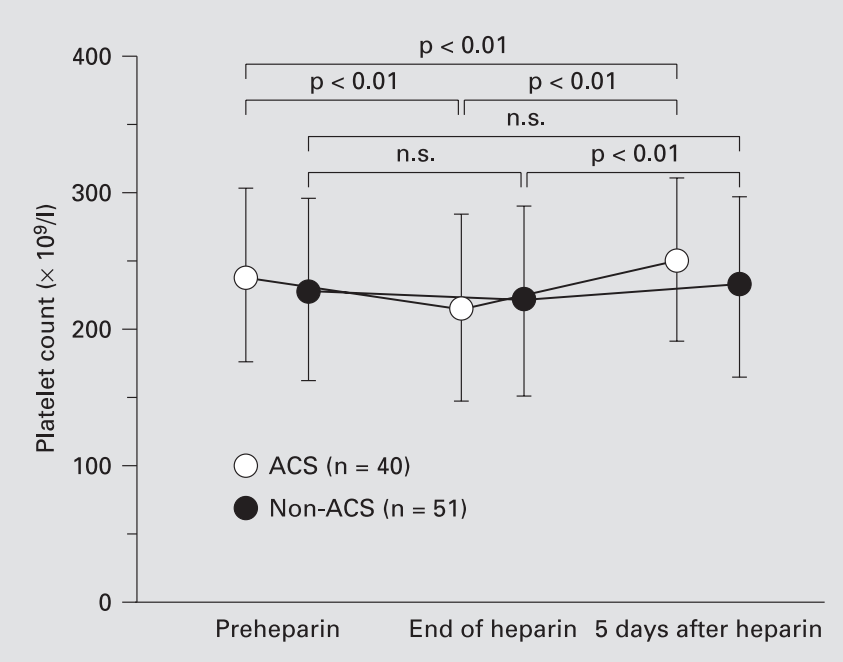

Fig. 1. Platelet count before and immediately after heparin treatment in ACS and non-ACS patients (mean \pm SD).

\section{Discussion}

Some studies have provided evidence that endothelial damage contributes to thrombotic complications in HIT. Serum from HIT patients reacted with the damaged endothelium and affected the expression of tissue factor, caused a fibrinolytic deficit, and increased levels of soluble adhesion molecules [6]. The target of HIT antibodies was not only PF4 bound to heparin, but also PF4 in complexes with heparin-like molecules on the remodeled endothelium [7]. Also, the tissue factor expression plays an important role in thrombogenicity in the coronary atherosclerotic plaques in ACS patients [8]. In this study, ACS patients with preexisting HIT antibodies detected by ELISA frequently had thrombotic complications during PCI under anticoagulation with heparin. Thrombotic complications requiring intracoronary thrombolytic treatment were suspected to be more common in ACS patients carrying HIT antibodies.

A rapid onset type of HIT occurred very shortly after heparin infusion in patients who possessed HIT antibodies although the same patients showed no thrombocytopenia on recent heparin exposure. This type of HIT is defined by an unexpected fall in the platelet count caused by residual circulating HIT antibodies [9]. HIT antibodies are thought to be a novel, independent predictor of myocardial infarction at 30 days in patients presenting with ACS [10]. In this study, subjects with no history of

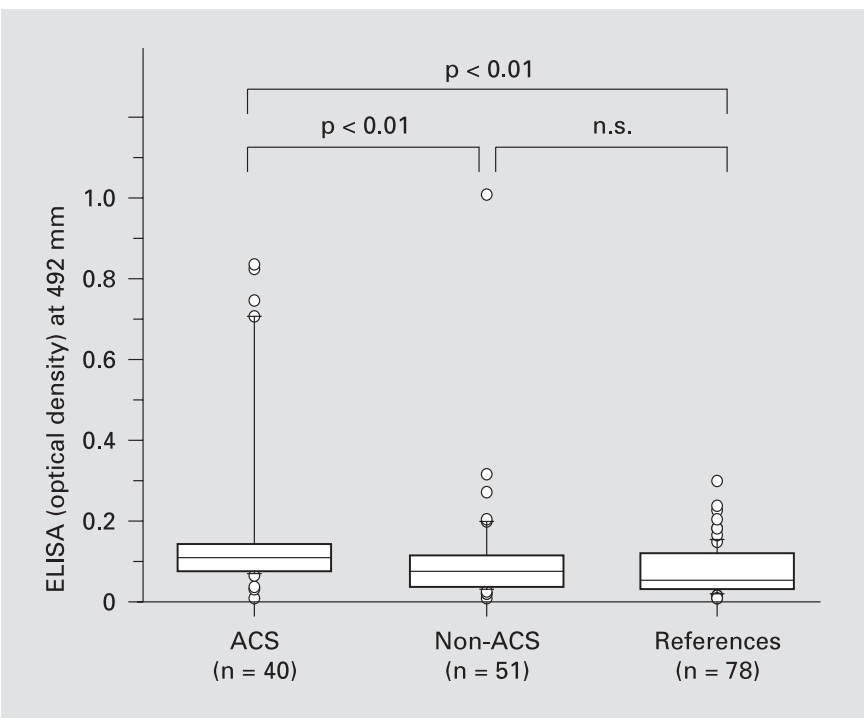

Fig. 2. HIT antibody titers of ELISA in three groups.

heparin exposure were selected from a thorough survey of medical records. Two HIT patients were found among 40 ACS patients suffering from thrombocytopenia and thrombotic complications during PCI. It was impossible to suspect that these patients with preexisting HIT antibodies were developing HIT shortly after heparin treatment. Two of the other 4 ACS patients with preexisting HIT antibodies developed thrombotic complications during PCI. Thus, cardiac patients with positive HIT antibodies who underwent $\mathrm{CABG}$ should not undergo surgery until the confirmation of negative seroconversion and avoid the use of heparin before and after surgery [11]. HIT antibodies detected in both ELISA and platelet aggregation assays were found in 11 out of 757 inpatients with no heparin exposure, suggesting that PF4 released from activated platelets could bind to endogenous heparin-like molecules on the endothelium and induce conformational changes of PF4 to neoantigen [2]. Early-onset HIT ( $<5$ days) was found in 3 of 76 serologically confirmed HIT patients with initially exposed heparin. As long as no HIT antibodies remain in the circulation, it is thought to be unlikely that HIT occurs within the first days of heparin treatment [12].

Based on the experience of this study, it is suggested that the preexisting HIT antibodies in patients with no history of heparin exposure were likely to predispose these individuals to early-onset HIT. Also, ACS patients who possess preexisting HIT antibodies developed throm- 
botic complications during PCI under initial heparin exposure even if they had no thrombocytopenia. Indeed, ACS patients compared with non-ACS patients are prone to enter a hypercoagulability [13], and the manipulation of PCI itself induces thrombogenicity due to artificial endothelial damage [14]. ACS patients with preexisting HIT antibodies showed more hypercoagulability on the addition of exogenous heparin, because they already had HIT antibodies together with both activated platelets and a damaged endothelium. Although this study examined only a relatively small number of ACS patients and patients with preexisting HIT antibodies, the following conclusion can be made. In order to prevent the development of HIT and thrombotic complications in ACS patients with preexisting HIT antibodies, it is necessary to recognize early-onset HIT in ACS patients without any history of heparin exposure and to treat these patients with alternatives to heparin.

\section{References}

-1 Suzuki S, Koide M, Sakamoto S, Yamamoto S, Matsuo M, Fujii E, Matsuo T: Early onset of immunological heparin-induced thrombocytopenia in acute myocardial infarction. Blood Coagul Fibrinolysis 1996;8:13-15.

2 Leitz H, Walenga JM, Fabbrini N, Lewis BE, Fasanella A, Messmore HL, Pifarre R: Pre-existence of anti-PF4-heparin antibodies in patients not exposed to heparins: relevance to clinical thrombocytopenia. Thromb Haemost 1997;77(suppl):562-563.

-3 Mattioli AV: Prevalence of anti-PF4/heparin antibodies and the HIT syndrome in cardiovascular medicine. Semin Thromb Hemost 2004;30:291-295.

4 Chong BH, Brugess J, Ismail F: The clinical usefulness of platelet aggregation test for the diagnosis of heparin-induced thrombocytopenia. Thromb Haemost 1993;69:344-350.

$>5$ Suzuki S, Sakamoto S, Adachi K, Mizutani K, Koide M, Ohga N, Miki T, Matsuo T: Effect of argatroban on thrombus formation during acute coronary occlusion after balloon angioplasty. Thromb Res 1995;77:369-373.
6 Fareed J, Walenga JM, Hoppensteadt DA, Jeske WP, Ahmad S, Leitz H, McKenna R, Messmore HL, Hass S: Soluble adhesion molecules in the HIT syndrome: pathophysiologic role and therapeutic modulation. Clin Appl Thromb Hemost 1999;5(suppl 1):s38-44.

7 Walenga JM, Jeske WP, Messmore HL: Mechanisms of venous and arterial thrombosis in heparin-induced thrombocytopenia. J Thromb Thrombolysis 2000;10:13-20.

$>8$ Nikolsky E, Dangas GD: Percutaneous interventions in patients with immune-mediated heparin-induced thrombocytopenia. Semin Thromb Hemost 2004;30:305-314.

$>9$ Warkentin TE, Kelton JG: Temporal aspects of heparin-induced thrombocytopenia. N Engl J Med 2001;344:1286-1292.

10 Williams RT, Damaraju LV, Mascelli MA Barnathan ES, Califf RM, Simoons ML, Deliargyris EN, Sane DC: Anti-platelet factor 4/ heparin antibodies, an independent predictor of 30-day myocardial infarction after acute coronary ischemic syndromes. Circulation 2003; 107:2307-2312.
11 Warkentin TE, Greinacher A: Heparin-induced thrombocytopenia and cardiac surgery. Ann Thorac Surg 2003;76:2121-2131.

12 Lubenow N, Kempf R, Eichner A, Eichler P, Carlsson LE, Greinacher A: Heparin-induced thrombocytopenia, temporal pattern of thrombocytopenia in relation to initial use or reexposure to heparin. Chest 2002;122:3742.

13 Merlini PA, Ardissino DA, Bauer KA, Oltrona L, Pezzano A, Bottasso B, Rosenberg RD, Mannucci PM: Persistent thrombin generation during heparin therapy in patients with acute coronary syndromes. Arterioscler Thromb Vasc Biol 1997; 17:1325-1330.

14 Suzuki S, Matsuo T, Kobayashi H, Matsuo M, Shimano C, Koide M, Sakamoto S: Effects of adjunctive anticoagulant (argatroban vs. heparin) during and after elective percutaneous transluminal coronary angioplasty on inflammatory, hemostatic and endothelial derived parameters in angina pectoris. Thromb Res 2000;98:269-279. 